\title{
The b-wave of the dark adapted flash electroretinogram in patients with advanced asymmetrical glaucoma and normal subjects
}

\author{
I M Velten, F K Horn, $M$ Korth, K Velten
}

\begin{abstract}
Aims-To evaluate whether the b-wave of the dark adapted flash electroretinogram (ERG) is affected by glaucomatous damage.

Methods-ERGs were recorded in 35 patients aged 33-65 years with advanced asymmetrical glaucomas (interocular difference of perimetric defects (mean deviation) $>2 \mathrm{~dB}$ between the two fellow eyes of the glaucoma patients, primary and secondary open angle and low tension glaucomas) and 17 normal subjects matched for age and sex using white flashes of a xenon discharge tube in a Ganzfeld stimulator. After 30 minutes of dark adaptation luminance response functions were obtained using flashes of increasing scotopic luminance (highest $9.4 \mathrm{~cd} / \mathrm{s} / \mathrm{m}^{2}$, lowest $5.5 \mathrm{log}$ units below it). The parameters $V_{\max }, n$, and $K$ of the Naka-Rushton equation were computed from the measurement values based on the usual fitting procedure. These parameters, together with b-wave amplitudes and implicit times for all flash intensities, were compared interocularly and between the normal subjects and those with glaucoma. Correlations were computed between interocular differences of the mean deviation and interocular differences of $V_{\text {max }}, n$, $\mathrm{K}$, b-wave amplitudes, and implicit times between the two fellow eyes of the patients with asymmetrical glaucomatous dam-
\end{abstract} age.

Department of Ophthalmology and University Eye Hospital, University of Erlangen-Nürnberg, Schwabachanlage 6, D-91054 Erlangen,

Germany

I M Velten

F K Horn

M Korth

University of Applied Sciences, Wiesbaden, von-Lade-Strasse 1 ,

D-65366, Geisenheim, Germany

K Velten

Correspondence to:

Dr I M Velten

isabel.velten@augen.imed.

uni-erlangen.de

Accepted 16 November 2000
Results-Implicit times were significantly longer $(p<0.005)$ in the glaucoma patients than in the normal group for flash intensities of $9.4,5.3,1.7,0.53$, and $0.17 \mathrm{~cd} / \mathrm{s} / \mathrm{m}^{2}$. b-Wave amplitudes did not differ significantly between the two study groups. Comparing the two fellow eyes of each patient with glaucoma, $V_{\max }$ was significantly higher in the less damaged eye than in the more damaged eye. The interocular differences in the mean deviation correlated significantly with the interocular differences in the b-wave amplitudes, implicit times, and $\mathbf{V}_{\text {max }}$.

Conclusions-These results suggest that glaucomas can lead to electrophysiologically measurable damage of the inner nuclear layer.

(Br F Ophthalmol 2001;85:403-409)
Glaucomas are known to lead primarily to damage of the retinal ganglion cell layer. Whether other inner, middle, and outer retinal structures can also be involved in glaucomatous changes has been the object of interest of many studies during the last years. Among others, glaucoma induced histological horizontal cell alterations in the human retina, ${ }^{1}$ increased glutamine uptake, ${ }^{2}$ and increased expression of glial fibrillary acidic protein ${ }^{3}$ in Müller cells were found. Histological studies to determine whether glaucomatous damage also leads to damage of the outer retinal layers, especially the photoreceptors, have given controversial results. ${ }^{45} \mathrm{~A}$ number of electrophysiological studies have been performed ${ }^{6-9}$ to establish whether the a-waves and b-waves of the flash electroretinogram (ERG) are affected by glaucomatous damage. While some of these studies could not find any significant change in ERG responses related to glaucomas, ${ }^{67}$ others $^{89}$ found significant changes in either the a-waves or the b-wave. The b-wave of the dark adapted flash ERG arises primarily from the on-bipolar cells, partially from the Müller cells. ${ }^{10}{ }^{11}$ It can therefore be regarded as a measure of the function of the middle retina, especially of the inner nuclear layer.

In contrast to previous investigations, the present study examines the b-wave of the dark adapted ERG using a light intensity function. The peak amplitude of the b-wave was followed from its threshold up to high intensities lying above the intensity of the ISCEV standard $^{12}$ bright flash. Each individual intensity response function was modelled by the Naka-Rushton equation ${ }^{13}$ and its three parameters $\left(\mathrm{V}_{\max }, \mathrm{n}\right.$, and $\left.\mathrm{K}\right)$ were obtained. Normal subjects show high interindividual variability in ERG responses. To reduce this variability an interocular comparison between the eye with the more advanced glaucoma damage and the less damaged fellow eye was used additionally in the comparison between the glaucomatous subjects and the normal group. This intraindividual interocular comparison enables a better determination of whether a relation exists between the stage of glaucoma damage and the impairment of the b-wave. It was thus the purpose of this study to determine electrophysiologically whether or not the middle retinal layers are included in advanced glaucomatous damage. To answer this question the study only used patients with long standing, advanced glaucomas with proven perimetric defects. 

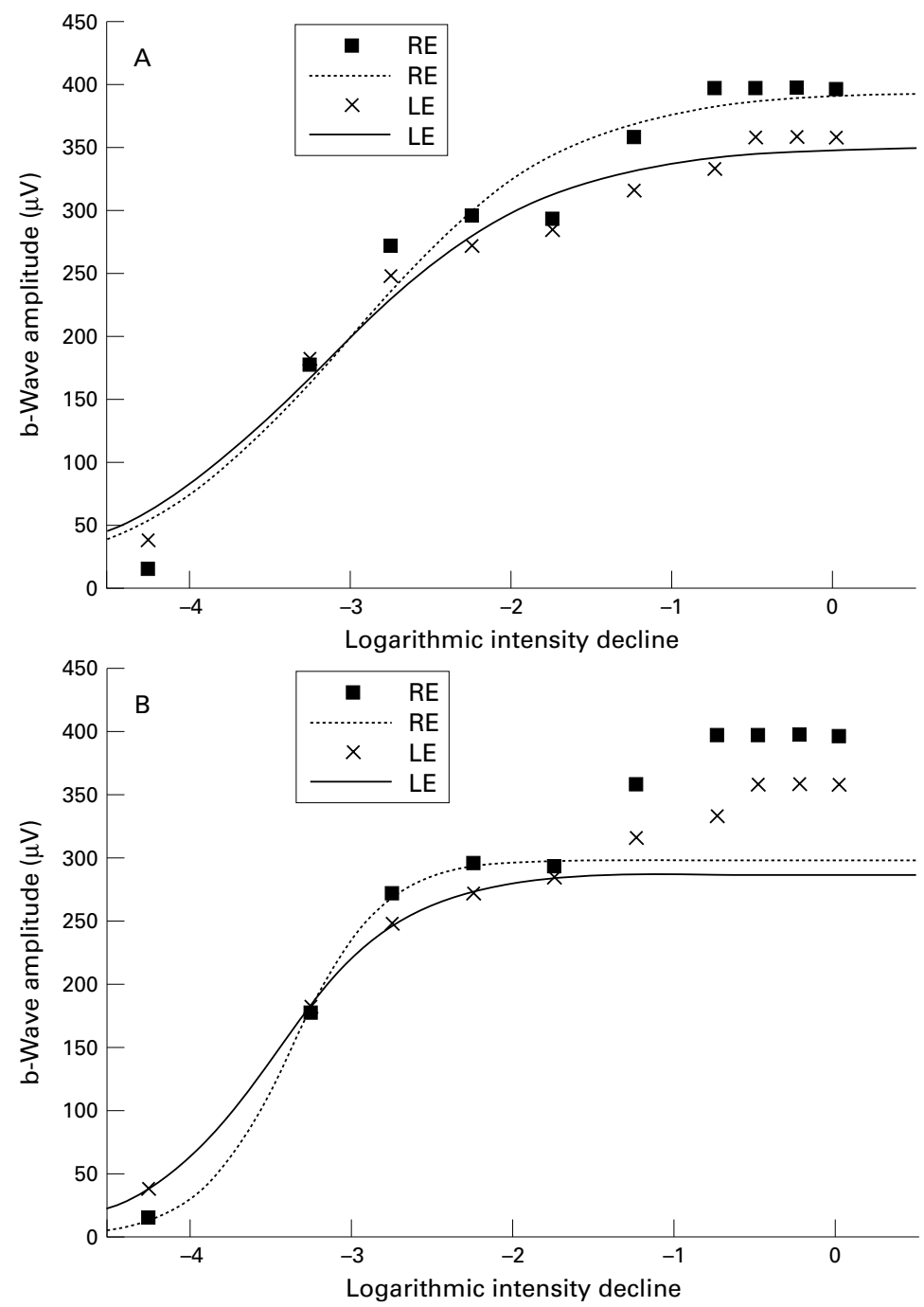

Figure 1 (A) Comparison between the intensity response data and the first model of the Naka-Rushton function fitted to all data points. The patient suffered from asymmetrical juvenile open angle glaucoma of the left eye (mean deviation in right eye (RE) $-1.0 \mathrm{~dB}$, mean deviation in left eye (LE) $8.7 \mathrm{~dB}$ ). The parameters of the Naka-Rushton equation are: $V=395 \mu \mathrm{m}, K=-3.02$ log units, $n=0.65$ for the right eye and $V=351 \mu \mathrm{m}, K$ $=-3.19 \log$ units, $n=0.63$ for the left eye. (B) Intensity response data of the right and left eyes of the same patient. In contrast to $(A)$, this figure demonstrates the second model of the Naka-Rushton equation with fit of the function to data points below -1.25 log units $\left(0.53 \mathrm{~cd} / \mathrm{s} / \mathrm{m}^{2}\right)$ and thus below the "second limb" of the intensity response function. The parameters of the second model of the Naka-Rushton equation are: $V_{\max }=298 \mu \mathrm{m}, \mathrm{K}=$ $-3.36 \log$ units, $n=1.55$ for the right eye and $V_{\max }=288 \mu \mathrm{m}, K=-3.47 \log$ units, $n=$ 1.06 for the left eye.
The white flashes were presented with increasing intensity with an interflash interval of 5 seconds (highest flash intensity $9.4 \mathrm{~cd} / \mathrm{s} / \mathrm{m}^{2}$, lowest $5.5 \log$ units below it). The lowest flash intensity was below the b-wave threshold in most subjects. Neutral density filters were used to achieve adequate flash intensity and each flash intensity was presented four times. An artefact rejection algorithm prevented unwanted signals such as eye movements from being averaged. After amplification (2 seconds, $500 \mathrm{~Hz}, 500 \mu \mathrm{V} / \mathrm{V}$ ) four sweeps $(300 \mathrm{~ms}$ in length) were averaged ( $500 \mathrm{~Hz}$ sampling rate) using a personal computer. The next higher flash intensity then followed. Steps of 0.5 and $0.25 \log$ units were used between two following flash intensities. The b-wave amplitude was measured from the trough of the a-wave to the peak of the b-wave or, when no a-wave was present, from the baseline to the peak. Apart from comparing the b-wave amplitudes and implicit times for all flash intensities measured, two models were used to describe the intensity response functions.

The models considered were the NakaRushton equation fit to all data points collected and the Naka-Rushton equation fit to the data points below the "second limb" of the function. The Naka-Rushton equation describes the roughly sigmoidal relation between the amplitude of the b-wave and the log flash intensity:

$$
\mathrm{V}(\mathrm{I}) / \mathrm{V}_{\max }=\mathrm{I}^{\mathrm{n}} /\left(\mathrm{I}^{\mathrm{n}}+\mathrm{K}^{\mathrm{n}}\right)
$$

Its parameters $\mathrm{V}_{\max }, \mathrm{n}$, and $\mathrm{K}$ were determined by the Levenberg-Marquardt method ${ }^{14}$ to achieve an optimal coincidence between the experimental intensity response measurements and the Naka-Rushton function. In this expression, $\mathrm{V}$ is the $\mathrm{b}$-wave amplitude in $\mu \mathrm{V}$, $\mathrm{V}_{\max }$ is the maximum amplitude of the b-wave for assumed infinite flash intensities, I is the luminance, $\mathrm{K}$ is the light intensity where the b-wave amplitude reaches half saturation (that is, $\mathrm{V}(\mathrm{K})=\mathrm{V}_{\text {max }} / 2$ ), and $\mathrm{n}$ is a dimensionless constant related to the slope of the intensity response function. Figure 1A shows a comparison between the measured b-wave amplitudes and a Naka-Rushton curve fitted to all data points. In Figure 1B the Naka-Rushton equation fitted to the data points below a light intensity of $-1.25 \log$ units $\left(0.53 \mathrm{~cd} / \mathrm{s} / \mathrm{m}^{2}\right)$, and thus below the "second limb" of the function, is shown.

The following factors are thought to be responsible for this second limb. Cone activity may contribute to the b-wave amplitude at higher stimulus intensities. Birch and Fish ${ }^{15}$ found closer correspondence of the data to the Naka-Rushton model when cone responses to scotopic stimuli were measured in isolation and subtracted from the scotopic b-wave. Secondly, the a-wave becomes more prominent at higher intensities. There is a close correspondence between the intensity at which the a-wave becomes evident with the intensity where the intensity response function shows an apparent saturation. ${ }^{16}$ For the second model applied in this study, only data points below a flash intensity of $-1.25 \log$ units $\left(0.53 \mathrm{~cd} / \mathrm{s} / \mathrm{m}^{2}\right)$ were used 
Table 1 Comparison of b-wave amplitudes and implicit times between normal subjects and those with glaucoma at all flash intensities

\begin{tabular}{|c|c|c|c|c|}
\hline \multirow[b]{2}{*}{ Flash intensity $\left(\mathrm{cd} / \mathrm{s} / \mathrm{m}^{2}\right)$} & \multicolumn{2}{|l|}{$b$-wave amplitudes $(\mu V)$} & \multicolumn{2}{|l|}{ Implicit time (ms) } \\
\hline & Normal v glaucoma & $p$ Value & Normal v glaucoma & $p$ Value \\
\hline 9.4 & $556(99) v 530(138)$ & NS & $43(5) v 51(7)$ & $<0.001$ \\
\hline $5.3(-0.25 \log )$ & $556(105) v 522(144)$ & NS & $46(5) v 51(8)$ & 0.005 \\
\hline $3.0(-0.5 \log )$ & $567(75) v 566(114)$ & NS & $44(9)$ v $53(9)$ & 0.007 \\
\hline $1.7(-0.75 \log )$ & $532(101) v 502(127)$ & NS & $46(4) v 51(8)$ & 0.001 \\
\hline $0.53(-1.25 \log )$ & $485(93) v 444(123)$ & NS & $47(2) \cup 55(12)$ & 0.001 \\
\hline $0.17(-1.75 \log )$ & $443(98)$ v $412(108)$ & NS & $53(6) v 63(11)$ & $<0.001$ \\
\hline $0.053(-2.25 \log )$ & $405(105)$ v $389(131)$ & NS & $78(9) \cup 83(11)$ & NS \\
\hline $0.017(-2.75 \log )$ & $366(111)$ v $337(123)$ & NS & $90(8) \vee 97(12)$ & 0.02 \\
\hline $0.0053(-3.25 \log )$ & $266(74) v 252(101)$ & NS & $106(13) v 110(13)$ & NS \\
\hline $0.00053(-4.25 \log )$ & $66(30) v 60(30)$ & NS & $125(22) v 131(17)$ & NS \\
\hline
\end{tabular}

Implicit times were significantly longer in the glaucoma group than in the normal group. b-Wave amplitudes did not differ significantly between the two study groups. The $\mathrm{p}$ values are the results of the unpaired $t$ test.

for fitting the Naka-Rushton function. Thus, the data points representing the second limb of the intensity response function were excluded.

SUBJECTS

Subjects were recruited from our glaucoma service and from hospital staff. Informed consent was obtained from each individual after explanation of the nature and possible consequences of the study according to the guidelines set by the Institutional Review Board.

In all, 35 patients with advanced asymmetrical open angle glaucomas, primary and secondary (pseudoexfoliation syndrome and pigmentary dispersion) open angle and low tension glaucomas and 17 normal subjects matched for age and sex were tested. All individuals satisfied the following criteria: refractive errors less than 9 dioptres (myopic or hyperopic), no previous cataract surgery, clear optic media, open anterior chamber angle, no systemic illnesses possibly influencing the eye such as diabetes mellitus, vascular or rheumatic diseases. The participants were between 33 and 65 years old (mean age 56 (SD 10) years).

All subjects underwent a full ophthalmological examination confirming a normal eye or excluding any ophthalmological diseases other than glaucoma. For both eyes in each subject the following examinations were conducted: best refracted visual acuity, perimetry with a computerised static projection perimeter (Octopus $500 \mathrm{EZ}$, program G1, two or three phases), slit lamp examination, gonioscopy, applanation tonometry, dilated fundus examination.

At the time of testing the intraocular pressure (IOP) was $\leqslant 21 \mathrm{~mm} \mathrm{Hg}$ in all eyes included. As a measure for the glaucoma damage static projection perimetry was used. The visual field indices described by Flammer $e t a l^{17}$ are calculated routinely by the programme G1 of the Octopus $500 \mathrm{EZ}$. Subjects performing in visual field testing with false positive and false negative responses of $>12 \%$ were excluded. Normal visual fields were accepted even if the test was the first one for the subject. Abnormal fields (mean deviation $>2.8 \mathrm{~dB}$, at least three contiguous test points $5 \mathrm{~dB}$ or more below the age corrected normal threshold) were accepted only if the subject had had at least two examinations with the Octopus 500 G1 perimetry.
Table 2 Interocular comparison of b-wave amplitude and implicit time between the more and less damaged fellow eye of each patient in the glaucoma group

\begin{tabular}{lll}
\hline & $p$ Value & \\
\cline { 2 - 3 } Flash intensity $\left(c d / s / m^{2}\right)$ & $b$-Wave amplitude & Implicit time \\
\hline 9.4 & $\mathrm{NS}$ & $0.006^{\star}$ \\
$5.3(-0.25 \mathrm{log})$ & $\mathrm{NS}$ & $0.003^{\star \star \star}$ \\
$1.7(-0.75 \mathrm{log})$ & $0.02^{\star}$ & $0.0015^{\star \star}$ \\
$0.53(-1.25 \mathrm{log})$ & $0.02^{\star}$ & $0.02^{\star}$ \\
$0.17(-1.75 \mathrm{log})$ & $0.006^{\star}$ & $\mathrm{NS}$ \\
$0.053(-2.25 \mathrm{log})$ & $0.02^{\star}$ & $\mathrm{NS}$ \\
$0.017(-2.75 \mathrm{log})$ & $0.04^{\star}$ & $\mathrm{NS}$ \\
$0.0053(-3.25 \mathrm{log})$ & $0.04^{\star}$ & $0.05^{\star}$ \\
$0.00053(-4.25 \mathrm{log})$ & $\mathrm{NS}$ & $\mathrm{NS}$ \\
\hline
\end{tabular}

Glaucomatous damage was classified by perimetric defects (mean deviation). Patients with glaucoma were included in the interocular comparison if the difference in mean deviation between both fellow eyes was $>2 \mathrm{~dB}$.

${ }^{\star} \mathrm{p} \leqslant 0.05,{ }^{\star \star} \mathrm{p} \leqslant 0.005,{ }^{\star \star \star} \mathrm{p} \leqslant 0.0005$ (Wilcoxon matched pairs signed ranks test).

The perimetric defect (mean deviation) was used to classify the more and less damaged fellow eye of each patient in the glaucoma group for the interocular comparison.

For the comparison between the normal and the glaucoma group only one eye per subject was included. In patients with glaucoma the eye with the more advanced glaucomatous damage was included. In the normal group one eye of each subject was chosen randomly.

\section{STATISTICAL ANALYSIS}

The b-wave amplitudes and implicit times of all flash intensities tested and parameters $\mathrm{V}_{\max }$,

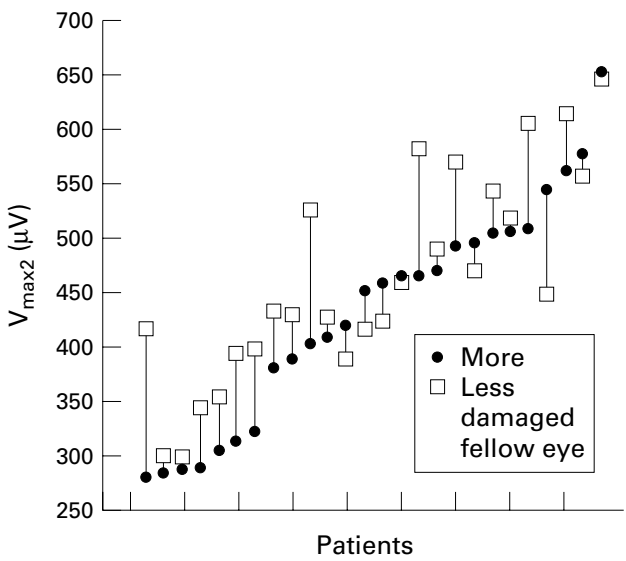

Figure $2 V_{\max 2}$ of the more and less damaged fellow eyes of all glaucoma patients included in the interocular comparison (interocular difference in mean deviation $>2 \mathrm{~dB}$ ). In 18 of the 26 patients $V_{\max 2}$ was higher in the fellow eye with the less advanced glaucomatous damage. 
$\mathrm{n}$, and $\mathrm{K}$ of the two models of the NakaRushton equation were compared between the normal subjects and those with glaucoma using the unpaired $t$ test. For the interocular comparison between the more and the less damaged fellow eye in the patients with glaucoma, $\mathrm{V}_{\max }, \mathrm{n}$, and $\mathrm{K}$ of the two models of the Naka-Rushton equation and the b-wave amplitudes and implicit times of all flash intensities were compared interocularly using the Wilcoxon matched pairs signed ranks test. In addition, the interocular differences of these parameters (right eye minus left eye) were correlated with the interocular differences of the perimetric defects (mean deviation) using Pearson's correlation coefficient. The level of significance was 0.05 for all statistical analyses.

\section{Results}

COMPARISON BETWEEN GLAUCOMA AND NORMAL GROUP

Table 1 shows the results of the unpaired $t$ test for the comparison of the b-wave amplitudes and implicit times for all flash intensities between normal subjects and those with glaucoma. Implicit times were significantly longer in the glaucoma group than in the normal group for several flash intensities, especially for high intensities. Parameters $\mathrm{V}_{\max }, \mathrm{n}$, and $\mathrm{K}$ of the two models of the Naka-Rushton equation and the b-wave amplitudes of all single flash intensities did not differ significantly between the two study groups.

\section{INTEROCULAR COMPARISON WITHIN THE}

GLAUCOMA GROUP

Only patients with a difference of $>2 \mathrm{~dB}$ in mean deviation between the more and the less damaged fellow eyes were included in the interocular comparison in the glaucoma group. Table 2 shows the results of the Wilcoxon matched pairs signed ranks test for the interocular comparison of the b-wave amplitudes and implicit times for all flash intensities. The amplitudes were significantly lower in the eye with the more advanced glaucoma damage than in the less damaged fellow eye for several flash intensities, especially in

Table 3 Correlations between interocular differences in b-wave amplitudes and implicit times with the interocular differences in the mean deviation in the glaucoma group

\begin{tabular}{|c|c|c|c|c|}
\hline \multirow[b]{3}{*}{ Flash intensity $(\mathrm{cd} / \mathrm{s} / \mathrm{m})$} & \multicolumn{4}{|c|}{$\begin{array}{l}\text { Pearson correlation between interocular differences in mean deviation } \\
\text { and interocular differences of: }\end{array}$} \\
\hline & \multicolumn{2}{|c|}{ b-Wave amplitude } & \multicolumn{2}{|l|}{ Implicit time } \\
\hline & $\begin{array}{l}\text { Correlation } \\
\text { coefficient }\end{array}$ & $p$ Value & $\begin{array}{l}\text { Correlation } \\
\text { coefficient }\end{array}$ & $p$ Value \\
\hline 9.4 & -0.405 & $0.02^{\star}$ & 0.554 & $0.001^{\star \star \star}$ \\
\hline $5.3(-0.25 \log )$ & -0.38 & $0.03^{\star}$ & 0.638 & $<0.001^{\star \star \star}$ \\
\hline $3.0(-0.5 \log )$ & -0.366 & NS & 0.735 & $<0.001^{\star \star \star}$ \\
\hline $1.7(-0.75 \log )$ & -0.498 & $0.003^{\star \star}$ & 0.582 & $<0.001^{\star \star \star}$ \\
\hline $0.53(-1.25 \log )$ & -0.465 & $0.006^{\star}$ & 0.237 & NS \\
\hline $0.17(-1.75 \log )$ & -0.521 & $0.002^{\star \star}$ & 0.0 .383 & $0.03^{\star}$ \\
\hline $0.053(-2.25 \log )$ & -0.443 & $0.01^{\star}$ & 0.106 & NS \\
\hline $0.017(-2.75 \log )$ & -0.386 & $0.03^{\star}$ & 0.288 & NS \\
\hline $0.0053(-3.25 \log )$ & -0.268 & NS & 0.321 & NS \\
\hline $0.00053(-4.25 \log )$ & 0.187 & NS & 0.356 & NS \\
\hline
\end{tabular}

The table shows the flash intensities for which interocular differences in the mean deviation between both fellow eyes of the glaucoma patients correlated significantly with the interocular differences of the b-wave amplitudes and implicit times. Correlation was better for implicit times than for b-wave amplitudes.

${ }^{\star} \mathrm{p} \leqslant 0.05,{ }^{\star \star} \mathrm{p} \leqslant 0.005,{ }^{\star \star \star} \mathrm{p} \leqslant 0.001$. the middle range of flash intensities measured, while implicit times showed a tendency to be significantly longer in the more damaged fellow eye for high flash intensities. The parameters $\mathrm{V}_{\max 1}$ and $\mathrm{K}_{1}$ of the first model of the Naka-Rushton equation (fit of the function to all data points) did not differ significantly between the two fellow eyes while $\mathrm{n}_{1}$ was significantly greater $(\mathrm{p}=0.02)$ in the less damaged eye. In the second model of the Naka-Rushton equation (fit of the function to the data points for flash intensities less than $\left.-1.25 \log \left(0.53 \mathrm{~cd} / \mathrm{s} / \mathrm{m}^{2}\right)\right), \mathrm{V}_{\max 2}$ was significantly lower in the eye with the more advanced glaucoma damage $(\mathrm{p}=0.009)$. Parameters $\mathrm{K}_{2}$ and $\mathrm{n}_{2}$ did not differ significantly between the two fellow eyes. Figure 2 plots $V_{\max 2}$ for the more and less damaged fellow eyes for each patient with glaucoma included in the interocular comparison. Correlations were computed between all interocular differences in the b-wave amplitudes and implicit times for all flash intensities and the interocular differences in the mean deviation, as well as for the interocular differences in $\mathrm{V}_{\max }, \mathrm{n}$, and $\mathrm{K}$ of the two models of the Naka-Rushton equation and the interocular differences in the mean deviation. The results of the Pearson correlation for the b-wave amplitudes and implicit times for all flash intensities are listed in Table 3. Both interocular differences in the b-wave amplitudes and interocular differences in the implicit times correlated significantly with the interocular differences in the mean deviation for several flash intensities. Implicit times showed a higher correlation coefficient for high flash intensities while b-wave amplitudes correlated best for flash intensities between $-0.75 \log \left(1.7 \mathrm{~cd} / \mathrm{s} / \mathrm{m}^{2}\right)$ and $-2.75 \log$ $\left(0.017 \mathrm{~cd} / \mathrm{s} / \mathrm{m}^{2}\right)$. Only the interocular differences in $\mathrm{V}_{\max 2}$ of the parameters $\mathrm{V}_{\max }, \mathrm{n}$, and $\mathrm{K}$ of the two models of the Naka-Rushton equation correlated significantly with the interocular differences in the mean deviation (Table 4).

Correlations between interocular differences in b-wave amplitudes, implicit times, and

Table 4 Correlation between interocular differences in the parameters $V_{\max }, n$, and $K$ of the two models of the Naka-Rushton equation with interocular differences in mean deviation

\begin{tabular}{|c|c|c|}
\hline \multirow{2}{*}{$\begin{array}{l}\text { Parameters of the two } \\
\text { models of the } \\
\text { Naka-Rushton equation }\end{array}$} & \multicolumn{2}{|c|}{$\begin{array}{l}\text { Pearson correlation of interocular } \\
\text { differences with interocular differences } \\
\text { in mean deviation }\end{array}$} \\
\hline & $\begin{array}{l}\text { Correlation } \\
\text { coefficient }\end{array}$ & $p$ Value \\
\hline $\begin{array}{l}\mathrm{V}_{\max 1} \\
\mathrm{n}_{1} \\
\mathrm{~K}_{1} \\
\mathrm{~V}_{\max 2} \\
\mathrm{n}_{2} \\
\mathrm{~K}_{2}\end{array}$ & $\begin{array}{r}-0.320 \\
-0.318 \\
0.043 \\
-0.489 \\
-0.133 \\
-0.296\end{array}$ & $\begin{array}{l}\text { NS } \\
\text { NS } \\
\text { NS } \\
0.003^{\star \star} \\
\text { NS } \\
\text { NS }\end{array}$ \\
\hline \multicolumn{3}{|c|}{$\begin{array}{l}\mathrm{V}_{\max }=\text { maximum amplitude of the } \mathrm{b} \text {-wave for assumed infinite } \\
\text { flash intensities; } \mathrm{K}=\text { light intensity where } \mathrm{b} \text {-wave amplitude } \\
\text { reaches half saturation; } \mathrm{n}=\text { a dimensionless constant related to } \\
\text { the slope of the intensity response function. } \\
\text { Of parameters } \mathrm{V}_{\max }, \mathrm{n} \text {, and } \mathrm{K} \text { of the two models of the } \\
\text { Naka-Rushton equation used in this study (model } 1 \text { : fit of the } \\
\text { function to all data points, model } 2: \text { fit of the function to all data } \\
\text { points below }-1.25 \log \text { units }\left(0.53 \mathrm{~cd} \mathrm{~s} / \mathrm{m}^{2} \text { ), only the interocular }\right. \\
\text { differences in } \mathrm{V}_{\max 2} \text { of the second model correlated significantly } \\
\text { with the interocular differences in mean deviation. }\end{array}$} \\
\hline
\end{tabular}


Table 5 Independent analyses for high tension glaucomas (HTG) and low tension glaucomas (LTG)

\begin{tabular}{|c|c|c|c|c|c|c|c|c|}
\hline \multirow[b]{4}{*}{ Flash intensity $\left(\mathrm{cd} / \mathrm{s} / \mathrm{m}^{2}\right)$} & \multicolumn{8}{|c|}{ Pearson correlation between interocular differences in mean deviation and interocular differences of: } \\
\hline & \multicolumn{4}{|c|}{$b$-Wave amplitude } & \multicolumn{4}{|c|}{ Implicit time } \\
\hline & \multicolumn{2}{|c|}{ Correlation coefficient } & \multicolumn{2}{|l|}{$p$ Value } & \multicolumn{2}{|c|}{ Correlation coefficient } & \multicolumn{2}{|l|}{$p$ Value } \\
\hline & HTG & $L T G$ & $H T G$ & $L T G$ & $H T G$ & $L T G$ & $H T G$ & $L T G$ \\
\hline 9.4 & -0.600 & 0.031 & $0.003^{\star \star}$ & NS & 0.556 & 0.461 & $0.007^{\star}$ & NS \\
\hline $5.3(-0.25 \log )$ & -0.567 & 0.036 & $0.006^{\star}$ & NS & 0.635 & 0.632 & $0.001^{\star \star \star}$ & $0.03^{\star}$ \\
\hline $3.0(-0.5 \log )$ & -0.646 & 0.150 & $0.001^{\star \star \star}$ & NS & 0.796 & 0.646 & $0.001^{\star \star \star}$ & $0.04^{\star}$ \\
\hline $1.7(-0.75 \mathrm{log})$ & -0.709 & 0.114 & $<0.001^{\star \star \star}$ & NS & 0.618 & 0.574 & $0.003^{\star \star}$ & $0.04^{\star}$ \\
\hline $0.53(-1.25 \log )$ & -0.624 & 0.040 & $0.002^{\star \star}$ & NS & 0.279 & 0.419 & NS & NS \\
\hline $0.17(-1.75 \log )$ & -0.660 & -0.200 & $0.001^{\star \star \star}$ & NS & 0.689 & -0.0003 & $0.001^{\star \star \star}$ & NS \\
\hline $0.053(-2.25 \log )$ & -0.586 & -0.147 & $0.005^{\star \star}$ & NS & 0.317 & -0.191 & NS & NS \\
\hline $0.017(-2.75 \log )$ & -0.570 & 0.116 & $0.007^{\star}$ & NS & 0.398 & 0.060 & NS & NS \\
\hline $0.0053(-3.25 \mathrm{log})$ & -0.525 & 0.269 & $0.015^{\star}$ & NS & 0.501 & 0.027 & $0.02^{\star}$ & NS \\
\hline $0.00053(-4.25 \log )$ & 0.231 & 0.049 & NS & NS & 0.472 & 0.269 & NS & NS \\
\hline
\end{tabular}

Correlations between the interocular differences in the mean deviation and the interocular differences in the b-wave amplitudes and implicit times showed a higher significance for "high tension glaucomas" (HTG) than for "low tension glaucomas" (LTG) when both subgroups were analysed independently.

${ }^{\star} \mathrm{p} \leqslant 0.05,{ }^{\star \star} \mathrm{p} \leqslant 0.005,{ }^{\star \star \star} \mathrm{p} \leqslant 0.001$.

parameters $\mathrm{V}_{\max }, \mathrm{n}$, and $\mathrm{K}$ and interocular differences in mean deviation were also computed independently for low tension glaucomas (13 of 35 glaucoma patients) and open angle glaucomas with a maximum IOP of $>21 \mathrm{~mm} \mathrm{Hg}$ ("high tension glaucomas", 22 of 35 patients). For low tension glaucomas only three correlations between the interocular differences in implicit times and the interocular differences in the mean deviation were significant while high tension glaucomas showed a higher significance when analysed independently (Table 5). Regarding parameters $\mathrm{V}_{\max 1,2}$, $\mathrm{n}_{1,2}$, and $\mathrm{K}_{1,2}$ of the Naka-Rushton equation, only the interocular differences in $\mathrm{V}_{\max 2}$ of the high tension glaucomas correlated significantly with the interocular differences in the mean deviation (Pearson's correlation coefficient $-0.611, p=0.003)$. There was no significant correlation between these parameters when low tension glaucomas were analysed independently.

\section{Discussion}

Implicit times were significantly longer in the glaucoma group than in the normal subjects for flash intensities between 9.4 and $0.017 \mathrm{~cd} / \mathrm{s} / \mathrm{m}^{2}$. b-Wave amplitudes and parameters $\mathrm{V}_{\max }, \mathrm{n}$, and $\mathrm{K}$ of the Naka-Rushton equation did not differ significantly between the two study groups. Hood and Birch ${ }^{18}$ found implicit times to be a good measure of inner nuclear layer function. Thus, one can assume that inner nuclear layer function is impaired in subjects with advanced glaucomas compared with normal subjects. b-Wave amplitudes and parameters $\mathrm{V}_{\max }, \mathrm{n}$, and $\mathrm{K}$ did not differ significantly between normal subjects and those with glaucoma. One reason might be that there is a high interindividual variability in ERG responses in normal subjects. Even if differences in b-wave amplitudes and parameters $\mathrm{V}_{\max }, \mathrm{n}$, and $\mathrm{K}$ of the Naka-Rushton equation (which are related to b-wave amplitudes) exist, these differences might be obscured by the high interindividual variability.

To avoid influences of this interindividual variability on statistical analysis, a second focus of this study was on the interocular comparison between more and less damaged fellow eyes of subjects with glaucoma. Perimetric defects (mean deviation) were chosen to classify the amount of glaucoma damage. The b-wave amplitudes were significantly higher and implicit times shorter in the eyes with the less advanced glaucoma damage for a number of flash intensities. Accordingly, the interocular differences in the amplitudes and implicit times correlated significantly with the interocular differences in the mean deviation. These electrophysiological results suggest that glaucomas lead to electrophysiologically measurable impairment of the inner nuclear layer and that this impairment advances with progression of perimetric defects.

Only patients with advanced long standing glaucomas with perimetric defects on repeated examinations were included in the study. Thus, one cannot conclude from the results of this study the stage of glaucoma at which impairment of the inner nuclear layer occurs, and whether or not it may be present before perimetric defects occur. Whether this electrophysiologically measurable impairment of the inner nuclear layer means histological alterations or only functional impairment can only be answered by histological examination. Janssen and coworkers ${ }^{1}$ found glaucoma induced histological horizontal cell alterations in the human retina in the neighbourhood of the on-bipolar cells. Even glaucoma induced histological damage of the outer retinal layers, especially the photoreceptors, has been found by some authors, ${ }^{5}$ while others did not detect a significant loss or change of photoreceptors in subjects with primary open angle glaucomas. ${ }^{4}$

Several electrophysiological studies have been performed to determine whether or not retinal structures other than the ganglion cell layer are affected by glaucomatous damage. The first major study of flash ERGs in glaucomas was performed by Leydhecker in $1950 .^{6}$ He investigated patients with primary open angle and angle closure glaucomas after $5 \mathrm{~min}$ of dark adaptation and did not find any correlation between visual function and ERG responses. Francois ${ }^{7}$ also found mainly normal ERG responses in open angle glaucomas except in patients with accompanying retinal alterations such as in some secondary open 
angle glaucomas. In contrast to these studies, Fazio and coworkers ${ }^{8}$ detected significant changes such as longer implicit times and smaller amplitudes in 14 patients with advanced primary open angle glaucomas compared with normal subjects in several ERG parameters (photopic a-wave implicit time, dark adapted bright flash a-wave amplitude, and dark adapted bright flash a- and b-wave implicit times). Similar results were obtained by Vaegan and coworkers ${ }^{9}$ who studied flash ERG changes in patients with simple optic atrophy and glaucomas. In patients younger than 55 years they found significant glaucomatous ERG changes such as reduction in oscillatory potentials, delayed implicit times, and reduced amplitudes of a-waves and b-waves which increased with disease severity. A decreased near threshold scotopic b-wave in glaucomas was found by Korth and coworkers. ${ }^{19}$ The results of Fazio, ${ }^{8}$ Vaegan, ${ }^{9}$ and Korth ${ }^{19}$ are consistent with the findings of the present study.

In contrast to the previous studies, we used an intensity response function following the b-wave from its threshold to high flash intensities where saturation of the b-wave was reached in all subjects. All recordings were performed under conditions according to the ISCEV standard. ${ }^{12}$ The idea was to obtain more information about the behaviour of the b-wave using an intensity response function over a wide range of flash intensities. However, application of the Naka-Rushton equation did not improve the separation between normal and glaucomatous subjects or between the more and less damaged glaucomatous fellow eyes compared with the analyses of the b-wave amplitudes and implicit times at the single flash intensities.

In the comparison between the normal and the glaucomatous group only the implicit times, but not the b-wave amplitudes, differed significantly. Thus, it is obvious that parameters $\mathrm{V}_{\max }, \mathrm{n}$, and $\mathrm{K}$ of the Naka-Rushton equation, which are fitted to the b-wave amplitudes at the single flash intensities, do not differ significantly either. In the interocular comparison in subjects with glaucoma b-wave amplitudes were significantly higher in the less damaged fellow eyes for flash intensities between $1.7(-0.75 \mathrm{log})$ and 0.0053 $(-3.25 \log ) \mathrm{cd} / \mathrm{s} / \mathrm{m}^{2}$ (Table 2) but not for the higher flash intensities $(9.4,5.3$, and $3.0 \mathrm{~cd} / \mathrm{s} /$ $\mathrm{m}^{2}$ ). This explains why the parameters $V_{\max }$ and $\mathrm{K}$ of the first model of the Naka-Rushton equation did not differ significantly between the asymmetrically damaged fellow eyes of the glaucoma patients. Thus, a second model of the Naka-Rushton equation already published by Peachy $e t a l^{16}$ was applied which uses a fit of the equation to the data points below the "second limb" of the function, neglecting the four highest flash intensities. In this second model $\mathrm{V}_{\max 2}$ was significantly lower in the eyes with less advanced glaucomatous damage than in the more damaged fellow eyes. The interocular differences in $\mathrm{V}_{\max 2}$ correlate significantly with the interocular differences in mean deviation. This model was also used by
Roecker and coworkers ${ }^{20}$ who did not find any significant differences in the ability to distinguish diabetic from non-diabetic subjects compared with the first model of the NakaRushton equation (with fit to all data points). In our study, however, this second model showed a better separation between the more and less damaged fellow eyes, probably because the b-wave amplitudes did not differ significantly for the two highest flash intensities which were excluded from the second model.

Correlations between the interocular differences in the mean deviation and the interocular differences in the b-wave amplitude, implicit times, and parameters $\mathrm{V}_{\max }, \mathrm{n}$, and $\mathrm{K}$ were analysed independently for high tension and low tension glaucomas. High tension glaucomas were found to correlate significantly better than low tension glaucomas which showed hardly any significant correlations. This might point to an electrophysiologically measurable difference in the behaviour of both glaucoma subgroups which needs to be investigated further.

In conclusion, the results of this study suggest that glaucomatous damage can lead to electrophysiologically measurable impairment of the inner nuclear layer. This functional impairment can be seen in a comparison between normal subjects and those with glaucoma of the implicit time of the b-wave, and also when two fellow eyes, one of which has more advanced glaucomatous damage than the other, are compared.

This study was supported by Deutsche Forschungsgemeinschaft, Bonn, "Sonderforschungsbereich Glaukome einschließlich Pseudoexfoliationssyndom" (SFB 539). Proprietary interests: none.

1 Janssen P, Naskar R, Moore S. Evidence for glaucomainduced horizontal cell alterations in the human retina. Ger f Ophthalmol 1996;5:378-85.

2 Carter-Dawson L, Shen F, Harwerth RS, et al. Glutamine immunoreactivity in Muller cells of monkey eyes with experimental glaucoma. Exp Eye Res 1998;66:537with.

3 Tanihara H, Hangai M, Sawaguchi S, et al. Up-regulation of glial fibrillary acidic protein in the retina of primate eyes with experimental glaucoma. Arch Ophthalmol 1997;115: $752-6$.

4 Kendell KR, Quigley HA, Kerrigan LA, et al. Primary openangle glaucoma is not associated with photoreceptor loss. Invest Ophthalmol Vis Sci 1995;36:200-5.

5 Panda S, Jonas JB. Decreased photoreceptor count in human eyes with secondary angle-closure glaucoma. Invest Ophthalmol Vis Sci 1992;33:2532-6.

6 Leydhecker G. The electroretinogram in glaucomatous eyes. Br F Ophthalmol 1950;34:550-4.

7 Francois J. L'electrographie dans le glaucoma. Acta Ophthalmol 1953;31:205-18.

8 Fazio DT, Heckenlevely JR, Deidre AM, et al. The electroretinogram in advanced open-angle glaucoma. Doc Ophthalmol 1986;63:45-54.

9 Vaegan, Graham SL, Goldberg I, et al. Flash and pattern electroretinogram changes with optic atrophy and glaucoma. Exp Eye Res 1995;60:697-706.

10 Knapp AG, Schiller PH. The contribution of on-bipolar cells to the electroretinogram of rabbits and monkeys. A study using 2-amino-4-phosphonobutyrate (APB). Vision Res 1984;24:1841-6.

11 Shiells RA, Falk G. Contribution of rod, on-bipolar, and horizontal cell light responses to the ERG of dogfish retina. Vis Neurosci 1999;16:503-11.

12 Marmor MF, Arden GB, Nilsson SEG, et al. International Standardisation Committee, 1989. Standard for clinical electrography. Arch Ophthalmol 1989;107:816-9.

13 Naka KI, Rushton WAH. S-potentials from colour units in the retina of the fish (Cyprinidae). F Physiol 1966;185:53655.

14 Marquardt DW. An algorithm for least squares estimation of nonlinear parameters. I Soc Ind Appl Math 1963;11:43141 . 
15 Birch DG, Fish GE. Rod ERGs in retinitis pigmentosa and cone-rod degeneration. Invest Ophthalmol Vis Sci 1987;28: 140-50.

16 Peachy NS, Alexander KR, Fishman GA. The luminance response function of the dark-adapted human electroretinogram. Vision Res 1989;29:263-70.

17 Flammer J, Drance SM, Augustiny L, et al. Quantification of glaucomatous visual field defects with automated perimetry. Invest Ophthalmol Vis Sci 1985;26:176-80.
18 Hood DC, Birch DG. A computational model of the amplitude and implicit time of the b-wave of the human ERG. tude and implicit time of the

19 Korth M, Nguyen NX, Horn F, et al. Scotopic threshold response and scotopic PII in glaucoma. Invest Ophthalmol Vis Sci 1994;35:619-25.

20 Roecker EB, Pulos E, Bresnick GH, et al. Characterization of the electroretinographic scotopic b-wave amplitude in diabetic and normal subjects. Invest Ophthalmol Vis Sci 1992;33:1575-83.

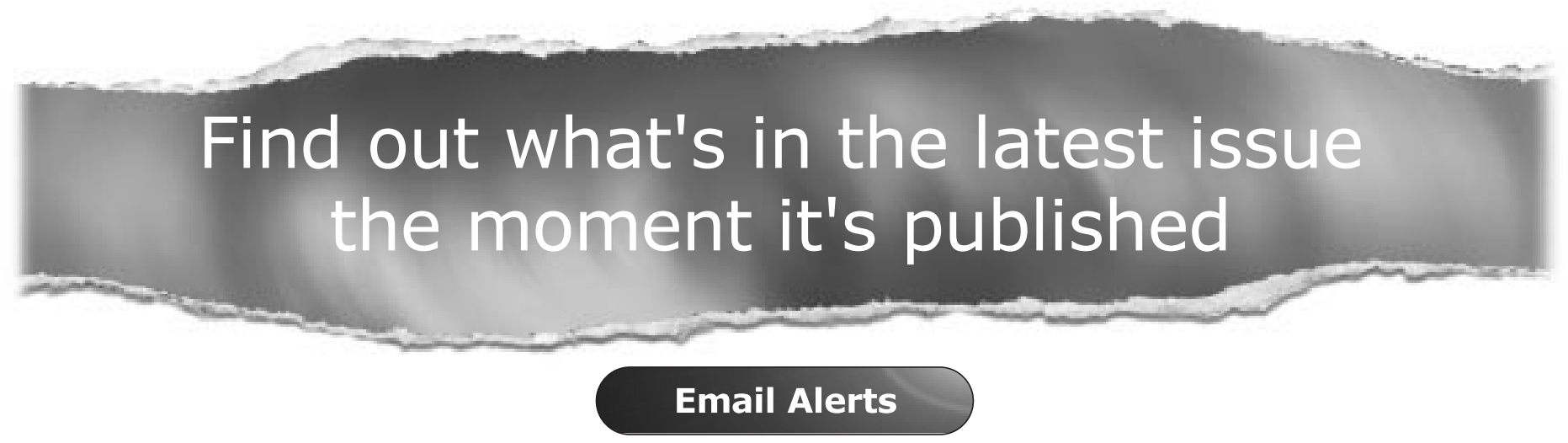

Sign up to receive the table of contents by email every month. You can select from three alerts: Table of Contents (full), TOC Awareness (notice only); British Journal of Ophthalmology related announcements.

www.bjophthalmol.com 